\title{
The discrimination decomposition index: a new instrument to separate statistical and taste-based discrimination using first- and second-generation immigrants
}

\author{
Giovanni Busetta and Maria Gabriella Campolo \\ Department of Economics, University of Messina, Messina, Italy, and \\ Demetrio Panarello \\ Department of Economics and Statistics, University of Udine, Udine, Italy
}

\begin{abstract}
Purpose - This article deals with the impact of ethnic origin on individual employability, focussing on the first stage of the hiring process. Deeply, the authors' goal is to fathom whether there is a preference for native job candidates over immigrants, decomposing the discrimination against minority groups into its statistical and taste-based components by means of a new approach.

Design/methodology/approach - The authors built up a data set by means of an ad hoc field experiment, conducted by sending equivalent fictitious CVs in response to 1000 real online job openings in Italy. The authors developed the discrimination decomposition index using first- and second-generation immigrants.

Findings - The authors' main result is that both first- and second-generation immigrants are discriminated compared to Italians. In between the two categories, second-generation candidates are discriminated especially if their ethnicities are morphologically different from those of natives (i.e. Chinese and Moroccans). This last finding is a clear symptom of discrimination connected to taste-based reasons. On the other hand, firstgeneration immigrants of all nationalities but Germans are preferred for hard-work jobs.

Originality/value - The authors develop the discrimination decomposition index to measure the proportion of the two kinds of discrimination (statistical and taste-based) over the total one and apply a probit model to test the statistical significance of the difference in treatment between the three groups of natives, first-generation and second-generation immigrants.
\end{abstract}

Keywords Economics of ethnic minorities, Field experiment, Fictitious résumés, Callback rate, Hiring process, Italy, Italian labour market, Race and gender discrimination, Ethnicity, Employment discrimination,

Discrimination measure, Probit model

Paper type Research paper

\section{Introduction}

Migration to Italy is a quite recent phenomenon that moved the state from an emigration country to a new immigration one (Bauer et al., 2000; Giacalone et al., 2019). While in the first half of the 1970s, the net inflow was mainly due to natives returning from the northern European countries, the situation has changed starting from the 1990s. In this respect, the Italian National Institute of Statistics (ISTAT) reports that $5 \mathrm{~m}$ immigrants were living in Italy on 1st January 2015 ( $8.2 \%$ of the population), with Romanians ( $22.6 \%$ of all the immigrants), Albanians (9.8\%) and Moroccans (9.0\%) as the three major communities (Istat, 2015).

\section{JEL Classification - C93, J15, J71}

(C) Giovanni Busetta, Maria Gabriella Campolo and Demetrio Panarello. Published by Emerald Publishing Limited. This article is published under the Creative Commons Attribution (CC BY 4.0) licence. Anyone may reproduce, distribute, translate and create derivative works of this article (for both commercial and non-commercial purposes), subject to full attribution to the original publication and authors. The full terms of this licence may be seen at http://creativecommons.org/licences/by/4.0/legalcode

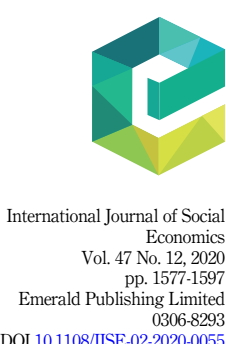

DOI 10.1108/IJSE-02-2020-0055 
IJSE

47,12

One of the most important factors to define the success of immigrants' integration is their participation in the labour market. In this respect, the situation in Italy seems not to be favourable. Indeed, recent immigrants to Italy seem to struggle in the labour market, dealing with significantly lower wages (Venturini and Villosio, 2008) and higher unemployment rates (Istat, 2013). Moreover, they are usually forced to find employment in lower-skilled occupations for which they are overqualified (Riva and Zanfrini, 2013). Immigrants earn about $20 \%$ less than Italians, skills and jobs being equal. This gap doubles to about $40 \%$ in terms of family disposable income (Saraceno et al., 2013), and discrimination further increases when we consider female candidates. In this respect, Italy, like most developed countries, is characterised by a substantial gender gap in the labour market. In the Global Competitiveness Report 2014-2015, "Female participation in the labour force", Italy is ranked 93rd out of 144 countries (Schwab and Sala-i-Martin, 2015).

The results from the Istat's (2015) "Quarterly Labour Force Survey" suggest that the main difficulties in entering the labour market reside in poor knowledge of Italian language, nonrecognition of qualifications from abroad and socio-cultural reasons. Are these the only reasons why firms discriminate against immigrants?

To answer this question, we jointly analyse first- and second-generation candidates to Italian job offers, to understand whether ethnic and gender discrimination occurs in the Italian labour market during the first step of the hiring process. To do so, we use the difference in callback rates between natives, second-generation immigrants and firstgeneration ones, presenting a new approach to decompose discrimination against minority groups into its statistical and taste-based components.

Altonji and Pierret (2001) show that employees are likely to be discriminated for statistical reasons with regard to easily observable characteristics, but not with regard to race. On the other hand, taste-based discrimination is often connected to stereotypical characteristics such as race. In this respect, Knowles et al. (2001) proposed a test to separate statistical and tastebased discrimination in the context of disparities in motor vehicle searches by the American police. Following their idea, police officers, in order to maximise arrests, tend to be more concentrated on African-American drivers than on Whites. They show that this happens not only because they consider race to be connected with the likelihood of finding cars carrying contraband (statistical discrimination), but also as a result of simple racial prejudice (tastebased discrimination).

While first-generation immigrants in our analysis were born and educated in their native country, second-generation ones were born in Italy and received Italian education. Thus, while discrimination against first-generation immigrants may be determined by productivity-related factors (e.g. different skills and/or linguistic gaps, due to the different education received and so it can be considered connected to statistical reasons), discrimination against second-generation ones is more likely to come from taste-based reasons, with them being Italian mother tongue individuals who always lived in Italy. Using this theoretical approach, we construct a new discrimination decomposition index (DDI), which considers the relative difference between Italian and second-generation candidates to be connected to taste-based reasons and the one between second- and first-generation ones to be a sign of statistical discrimination.

In this respect, we decide to study the first step of the hiring process because, if discrimination is going to occur, it is easier for firms not to interview a potential worker, than firing him/her (Lahey, 2008).

Discrimination against immigrants in the labour market is a widespread phenomenon in Europe. Indeed, most labour market indicators such as unemployment rates, share of temporary contracts and share of involuntary part-time contracts concerning migrants are worse than those concerning natives in most European countries (Quintano et al., 2019). Moreover, migrants are usually segregated in the workplace, holding jobs with poorer 
working conditions compared to natives (Orrenius and Zavodny, 2009). For instance, in Germany, this segregation is higher in agriculture, mining, construction and the service sector (Glitz, 2014). In Italy, immigrants are usually working in unskilled manual jobs and are very unlikely to be self-employed (Fullin and Reyneri, 2011). As Italy is a recently growing immigration country, we want to understand if second-generation immigrants are discriminated differently with respect to first-generation and native candidates. Indeed, Italy is particularly relevant because this is the first time in which second-generation immigrants strongly approach the labour market. Moreover, we want to analyse whether discrimination based on ethnicity depends on candidate's gender, on skills and abilities required by the job and on the level of customer contact required (front vs back office). We concentrate on the difference in treatment between first- and second-generation immigrants because, while discrimination against the former is compatible with enterprises' profitmaximising behaviour, discrimination against the latter is not (Becker, 1971).

Finally, we analyse whether the ethnic provenience of the candidates impacts differently on their level of discrimination. To estimate the different level of discrimination between Italians and immigrants and within immigrants, we conduct several probit regression models using callback as dependent variable. Our results show that discrimination against immigrants works for both first- and second-generation candidates, demonstrating the existence of both statistical and taste-based discrimination in the Italian labour market (see Busetta et al., 2018).

The rest of the article is organised as follows. In Section 2 a review of the concerning literature is presented. The experimental design is described in Section 3. In Section 4 we present data and methodology. In Section 5 we present the results. The last section concludes our study.

\section{Theoretical background}

Economic theory splits discrimination into two types: statistical, when the judgement of an individual is determined by group characteristics rather than individual ones; and tastebased, which occurs when the preference for a certain group of individuals over another is based on tastes, rather than any economic rationale (see Lahey, 2008 for a review of this literature). While, in the case of imperfect information, statistical discrimination is considered efficient (Arrow, 1973), taste-based discrimination is always inefficient in terms of overall social welfare (Becker, 1971).

We refer to discrimination based on gender or race in the labour market when a person's gender or provenience becomes a crucial factor in decisions about hiring, wages, terminations, promotions, leaves and benefits.

In terms of racial and ethnic preferences, taste-based discrimination concerns the situation in which the employer discriminates against a group of individuals irrespective of other information he or she has about the applicants (Zschirnt and Ruedin, 2016). This includes xenophobia and racism. In this way, recruiters do not act in a purely profit-maximising manner, but "an avoidance of the psychic cost of contact with the "wrong' race [...] takes precedence" (Riach and Rich, 1991, p. 247). For this reason, recruiters without racial preferences have a competitive advantage, which should bring to the elimination of racial discrimination in the labour market. On the other hand, statistical discrimination concerns the situation in which members of a specific group are discriminated against because the recruiter is lacking information (Arrow, 1972; Phelps, 1972) and ethnicity acts as a proxy for unobserved information. For this reason, a recruiter will not always succeed in hiring the most qualified applicants; however, if hiring decisions are taken on a regular basis, statistical discrimination may be regarded as an acceptable trade-off between the effort to obtain more information about an applicant and the recruitment of the most productive employee (Bursell, 2007).

Men are usually considered more productive than women, and natives more than immigrants, without taking any objective factor into account (Andriessen et al., 2010); for this 
IJSE

47,12

reason, women and immigrants are usually discriminated against in favour of men and natives. On the contrary, there are also cases in which men or natives are discriminated against on the basis of gender or provenience; these cases are usually referred to as "reverse discrimination" (Bursell, 2014). The most studied question in the literature on gender- and race-based discrimination is whether there is a discriminatory wage gap between women and men, and immigrants and natives, and what share of the gap is attributable to taste-based discrimination or to statistical discrimination (Bertrand and Mullainathan, 2004; Neumark, 2004; Oreopoulos, 2011).

To test the potential level of discrimination in the labour market, several experiments have been performed in the last 50 years (see Rich, 2014; Baert, 2018; Lippens et al., 2020). Nowadays, there is a substantial body of literature demonstrating several kinds of discrimination in the labour market which can split individuals into minority and majority groups, such as the ones based on gender (Olian et al., 1988; Raijman and Semyonov, 1997; Arai et al., 2016; Bygren et al., 2017), race (Riach and Rich, 2002; Bertrand and Mullainathan, 2004; Oreopoulos, 2011; Bursell, 2014), age and disability (Lahey, 2008), sexual orientation (Drydakis, 2009), body weight (Busetta et al., 2020a) and attractiveness (Busetta et al., 2020b). These studies show that, on average, résumés sent by minority groups' members are evaluated more negatively than identical résumés attributed to majority groups' ones.

Statistical discrimination and taste-based discrimination have been deeply analysed. For example, Kaas and Manger (2012) sent two different applications in Germany, one with a Turkish-sounding name and one with a typical German name. Furthermore, two different application types are included in the study: one contains reference letters from previous employers, stating favourable information about the applicant's personality, while the other type does not. Restricting the sample to applications including reference letters, discrimination disappears, and this finding could be a shred of evidence for statistical discrimination.

Nunley et al. (2015) answered online job postings from fictitious job seekers in the USA. For jobs that require customer interaction, the interview rate gap becomes higher, which can be considered evidence for taste-based discrimination.

In this respect, Carlsson (2010) sent qualitatively identical résumés finding that the probability of being invited to a job interview is significantly lower for immigrants than for natives, but that it does not essentially change between first- and second-generation immigrants. Midtbøen (2016) performed a similar experiment in Norway. Their results show that applicants with Norwegian names on average are 25\% more likely to receive a callback for a job interview than equally qualified applicants with Pakistani names, even if candidates are second-generation immigrants.

Even if great attention has turned to evaluate differences between taste-based and statistical discrimination, none of these studies has ever used first- and second-generation immigrants to control for the difference between statistical and taste-based discrimination. The only other study using first- and second-generation immigrants to separate statistical and taste-based discrimination is Busetta et al. (2018). Differently from the latter study, which applies a well-established methodological approach (the correspondence test), we propose a new index in order to calculate the share of statistical and taste-based discrimination on the total one. In the scientific literature, some famous attempts to develop indexes of discrimination have been those by Duncan and Duncan (1955), Shulman (1987), Chen and Zhang (2018) and Torrent-Sellens et al. (2018).

Duncan and Duncan (1955) developed a segregation index to measure inhomogeneity in the treatment of two groups of individuals (e.g. Black and White or women and men) across a set of occupations. Deeply, the index ranged from 0 to 100 for perfect integration and complete segregation, respectively.

Shulman (1987) constructed an index distinguishing between the wage and employment components of discrimination. They used information on the number of wage complaints of 
job discrimination and on the number of hiring and discharge complaints. Deeply, they used complaints received by the US Equal Employment Opportunity Commission in some given years, divided according to the labour force, race and sex of the complainants.

Chen and Zhang (2018) proposed a new method to decompose the total employment and wage discrimination of two labour groups - majorities and minorities - into an employment discrimination index, a wage discrimination index and then into the underpayment index to majorities and the overpayment index to minorities.

Torrent-Sellens et al. (2018) computed a labour discrimination index to measure job satisfaction, consisting of the sex, age, nationality, mobbing and sexual harassment dimensions.

None of the previous authors found a way to separate the influence of statistical discrimination from the taste-based one.

\section{Experimental design}

In order to test the difference between statistical and taste-based discrimination, we collected data through an ad hoc constructed field experiment carried out sending fictitious CVs to firms advertising real job openings in a certain period (July 2013 and October 2014), in which we sent thousands of fictitious résumés, answering to real online job postings.

Therefore, for each offer we prepared and sent 22 ad hoc CVs (in total 22000) - one for each fictitious identity that was previously generated accordingly - and then collected callbacks to a job interview from the firms, using them as a proxy of job opportunities. In this sense, we considered their difference as a good proxy of the discrimination between different candidates. We drew job advertisements from the main Italian job search websites, taking a simple random sample of postings every week.

We produced fictitious résumés based on the European format and structure. The identities were created as follows: 1 Italian man, 5 first-generation immigrant men, 5 secondgeneration immigrant men, 1 Italian woman, 5 first-generation immigrant women and 5 second-generation immigrant women. The immigrants were equally distributed and came from Romania, Albania, Morocco, People's Republic of China (the four most common foreign nationalities in Italy) and Germany (the most common nationality among "rich" Western countries). For each offer, identities were constructed with the same skills and information to be identical in every respect differing only by name, surname, gender, city of birth, postal address and e-mail address.

Keeping equal all the individual characteristics, except for gender and nationality, we concluded that differences in callback rates would necessarily come from discrimination based on such elements. In terms of education, on the one hand, we selected the most important schools and universities of their own country for first-generation immigrants. On the other hand, we chose the same Italian schools and universities for Italian and second-generation individuals. Furthermore, all the categories of candidates got the maximum marks at schools and universities. Finally, to avoid matching problems and to be competitive with respect to other applicants, for each different job offered we added the characteristics (i.e. education level, field of study, work experience, language and computer skills) which completely fulfilled the skills required by the firms to each association already made (name, surname and address). This approach ensured that perceived productivity characteristics on the supply side were held constant. Gender and country of origin were the only items which changed among the different CVs sent in response to the same job offer. Our idea is the following: while differences in callback rates between second- and first-generation candidates can be driven by statistical reasons, differences between Italian and second-generation individuals must necessarily be driven by the taste-based one. 
IJSE

47,12

Using this procedure, we thus sent $22 \mathrm{CVs}$, identical in every respect except for name and surname. In this respect, we used the most common names for each nationality in order to minimise the concerning bias. Indeed, our applicants were very similar in every respect for each kind of job offer, except for technical aspects which, as pointed out by Rooth (2009), "are very unlikely to be affecting our results".

The degree of differential treatment was quantified by using the difference between groups in the number of callbacks for a job interview.

Our design strategy, of sending fictitious CVs which exactly meet the firms' requirements, allowed us to eliminate matching problems as a possible explanation for the difference in the rate of response.

We classified all job openings according to whether the position involves face-to-face contact with the public. Deeply, we classified as front office jobs those which either explicitly stated that the job required face-to-face contact with people or where such contact could be unequivocally inferred from the job advertisement. Otherwise, the job is classified as back office. We then included in the first category, for instance, jobs belonging to fields such as sales and customer service. By contrast, we decided to include in the back office category jobs such as accounts management, budgeting, industrial engineering and computer programming.

Another distinction that we made was between jobs for which physical strength is required and jobs for which it is not. As for front and back office jobs, we classified as hard work either jobs for which physical strength is explicitly required or those for which it may be unequivocally inferred. Otherwise, they were classified as jobs not implying hard work.

The last characteristics that we considered in the analysis are the qualifications required. In this way, we divided job openings into offers requiring graduation, high school diploma and no qualification required.

\section{Data and methods}

\subsection{Data}

Responses were classified as callbacks if the employer requested an applicant to contact them (not just for clarification). According to a study released by Ladders, Inc. (Evans, 2012) and reported by Time, Huffington Post, Business Insider and Forbes, the average time for a recruiter to screen a new $\mathrm{CV}$ during the first step of the hiring process is $6 \mathrm{~s}$. As we sent $22 \mathrm{CVs}$ to each firm, the burden produced by our study to employers amounts to about $132 \mathrm{~s}$ : a little bit more than $2 \mathrm{~min}$ for each firm. Moreover, to minimise inconvenience to the employer, invitations were promptly declined since employers who contacted an applicant were contacted by e-mail saying that the applicant had accepted another position and was no longer looking for employment.

Our original sample consists of $22000 \mathrm{CVs}$ sent in response to 1000 job openings. We analysed callback rates to see whether some fictitious applicants were discriminated. The possible outcomes within the field experiment tradition are the following: both applicants are invited to an interview, only the majority/native applicant is invited to an interview, only the minority/foreign applicant is invited and none of them is invited. In cases where none is invited to an interview, we could consider it either as a case of equal treatment, because all the candidates are treated symmetrically (Cross et al., 1990), or as non-observations, since there are many reasons why applicants may be rejected before the employer even considers their ethnic background (Riach and Rich, 2002).

As we could not control for the reason why some firms do not answer to any of the candidates, we decided to follow the second approach restricting the sample to the ones that have replied to at least one CV (no. 229 companies, 5038 candidates). See Riach and Rich (2004) for a review of the articles restricting their sample in such a way. This is because we do 
not have enough information to evaluate why firms not contacting any of the candidates decided to do so (Table 1).

Table 2 shows the callback rates of each category before and after sample restriction. Callback rates are calculated by dividing the number of callbacks of each category by the number of CVs sent by the same category. While, obviously, callback rates of each category increase after restricting the sample, the concerning ranking between categories remains the same. Columns 3 and 5 of this table show rates of response for each category (i.e. the share of total callbacks obtained by each category), calculated by dividing the number of callbacks for each category by the total number of callbacks obtained by all the categories. Even if the callbacks change from complete to restricted sample, the same does not happen for the rates of response. In this sense, the proportion of positive answers obtained by each category in the sample remains almost the same. This result confirms that the distribution of callbacks does not change with restriction and that, consequently, no distortion is introduced.

Finally, the sample used in our study is formed by 458 Italian men and women, 2290 firstgeneration immigrants and 2290 second-generation ones. Considering the response rate, women are discriminated more than men, in each subsample. While the response rate for Italian people is equal to $52 \%(40 \%$ and $63 \%$ for women and men, respectively), the percentage decreases when considering foreigners: $24 \%$ for the first generation ( $18 \%$ women and $30 \%$ men) and $32 \%$ for the second generation (24\% women and $40 \%$ men). To investigate whether differences in response rates are statistically significant in our subsamples, we applied the proportion test between groups. With the average percentage of response rates in the sample (corresponding to 1035 positive answers) being $30 \%$, we conducted the aforementioned test between women and men in general (respectively 0.23 and $0.38, p<0.00)$ and between Italian and immigrants $(0.52$ and $0.28, p<0.00)$. Moreover, we replicated the same proportion test on the subsamples including only women ( 0.40 for Italian and 0.21 for immigrants, $p<0.00)$ and only men $(0.63$ for Italian and 0.35 for immigrants, $p<0.00$ ). Moreover, regarding the subsample of immigrants, we can observe significant differences between first- and second-generation immigrants $(0.24$ and $0.32, p<0.00)$.

\subsection{Discrimination decomposition index (DDI)}

The descriptive statistics show a widespread preference for Italian candidates over both firstand second-generation immigrants. Moreover, second-generation immigrants seem to be preferred over first-generation ones.

Following this idea, we can represent a line of discrimination which goes from a minimum to a maximum level, in which natives are the ones with the lowest associated degree of discrimination, while first-generation immigrants are the ones to whom the maximum level is

\begin{tabular}{|c|c|c|c|c|c|c|c|}
\hline & \multicolumn{3}{|c|}{ Complete $(\mathrm{CVs}$ sent $=22000)$} & \multicolumn{3}{|c|}{ Restricted $(\mathrm{CV}$ s sent $=5038)$} & \\
\hline & Proportion & S.D. & $N$ & Proportion & S.D. & $N$ & \\
\hline Italian & 0.09 & 0.287 & 2000 & 0.09 & 0.287 & 458 & \\
\hline First generation & 0.45 & 0.498 & 10000 & 0.45 & 0.498 & 2290 & \\
\hline Second generation & 0.45 & 0.498 & 10000 & 0.45 & 0.498 & 2290 & \\
\hline Woman & 0.50 & 0.500 & 11000 & 0.50 & 0.500 & 2519 & \\
\hline Front office & 0.46 & 0.498 & 10054 & 0.44 & 0.496 & 2200 & \\
\hline Hard work & 0.29 & 0.452 & 6314 & 0.27 & 0.447 & 1386 & \\
\hline Graduate & 0.24 & 0.426 & 5258 & 0.24 & 0.427 & 1210 & \\
\hline High school & 0.43 & 0.495 & 9526 & 0.43 & 0.495 & 2156 & Table 1. \\
\hline No title & 0.33 & 0.469 & 7216 & 0.33 & 0.471 & 1672 & Distribution of the total \\
\hline North-Centre & 0.77 & 0.420 & 16962 & 0.85 & 0.356 & 4290 & and restricted sample \\
\hline
\end{tabular}




\section{Nationality}

Italian

First generation

Second generation

Woman

Front office

Hard work

Education level

Graduate

Table 2.

High school

Callback rates and rates of response of the Geographical area complete and restricted sample

No title

$\begin{array}{ll}0.09 & 0.16 \\ 0.45 & 0.36 \\ 0.45 & 0.49 \\ & \\ 0.50 & 0.37 \\ 0.46 & 0.39 \\ 0.29 & 0.24 \\ & \\ 0.24 & 0.27 \\ 0.43 & 0.44 \\ 0.33 & 0.29 \\ & \\ 0.77 & 0.86 \\ 0.23 & 0.14\end{array}$

0.16

0.36

0.49

0.37

0.39

0.24

0.27

0.44

0.29

0.06

0.86
0.14
0.44

.29
0.08
0.04
0.86

0.14
0.52

0.24

0.32

0.22

0.27

0.26

0.34

0.31

0.26

0.30

0.30

associated. Somewhere in between, we will have the level of discrimination associated to second-generation immigrants, reasonably less discriminated than the first-generation ones, but more than natives (Figure 1).

It is possible to depict the two kinds of discrimination in terms of difference in the callback rates (C.B.) obtained by the various categories of candidates. Therefore, the phenomenon can be presented as in Figure 2.

While the difference in callback rates between second- and first-generation immigrants may be due to statistical reasons, the one between Italians and second-generation immigrants must necessarily be due to reasons based on taste. Following this idea, we can define total discrimination as the sum of statistical and taste-based discrimination.

Therefore, we introduce a discrimination decomposition index (henceforth, DDI), conditioned to C.B. rate native $>$ C.B. rate first generation, made of two components: the statistical discrimination index (SDI) and the taste-based discrimination index (TBDI).

$$
\begin{aligned}
& \mathrm{SDI}=\frac{\text { C.B. rate } 2 \text { nd gen }- \text { C.B. rate } 1 \text { st gen }}{\mid \text { C.B. rate native }- \text { C.B. rate } 1 \text { st gen } \mid} \\
& \text { TBDI }=\frac{\text { C.B. rate native }- \text { C.B. rate } 2 \text { nd gen }}{\mid \text { C.B. rate native }- \text { C.B. rate } 1 \text { st gen } \mid}
\end{aligned}
$$

While SDI and TBDI range from $-\infty$ to $+\infty$, their sum (total discrimination) equals to either +1 , when the discrimination against the minority group prevails, or -1 , if the prevalent discrimination is against the majority group.

If second and first generations get the same callback rate, the total discrimination is only determined by the taste-based discrimination component. When Italian and second-

Figure 1.

Levels of discrimination based on ethnicity

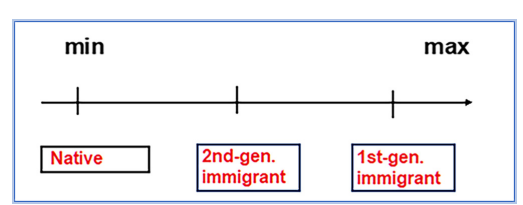


generation candidates receive the same number of callbacks, then the total discrimination is determined only by statistical reasons.

In Table 3 we present the direction of the total discrimination and of the DDI components, based on the comparison between the callback rates obtained by each category of candidates.

\subsection{Econometric analysis}

The objective of our work is to analyse whether discrimination based on ethnic origin affects the Italian labour market in terms of different opportunities of finding a job. Therefore, our estimates consider Italian candidates as the reference level. Immigrants are divided into firstand second-generation ones. We split immigrants by generation to separate statistical and taste-based discrimination and to create several interaction effect variables.

The main equation of interest looks at the effect of ethnicity on positive callback. Then, after examining the general characteristics of our sample and the association between the response rate and the nationality of the candidates, we estimated a probit regression model of the callbacks as a function of the candidate's sex, nationality, level of education, type of work and geographical area (Eqn 1).

$$
\begin{aligned}
& Y_{i}^{*}=\beta_{0}+\beta_{1} \text { North }- \text { Centre }_{i}+\beta_{2} \text { Woman }_{i}+\beta_{3} \text { Graduate }_{i}+\beta_{4} \text { High School }_{i} \\
& +\beta_{5} \text { Hard Work }_{i}+\beta_{6} \text { Front Office }_{i}+\beta_{7} \text { Employment Rate }_{i}+\beta_{8} \text { FirstGen }_{i} \\
& +\beta_{9} \operatorname{SecondGen}_{i}+\varepsilon_{i}
\end{aligned}
$$

where $Y^{*}$ is the latent variable reflecting the probability of the $i$-th subject of receiving a

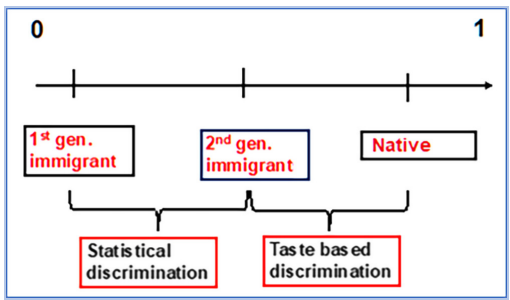

Figure 2.

Statistical and tastebased discrimination described in terms of

\begin{tabular}{|c|c|c|c|}
\hline \multicolumn{4}{|c|}{ DDI } \\
\hline Case & TBDI & SDI & Total discrimination \\
\hline Native > 2gen > 1gen & + & + & +1 \\
\hline Native > 1gen > 2gen & + & - & +1 \\
\hline Native $>$ 1gen $=2$ gen & + & 0 & +1 \\
\hline Native $=1$ gen $>2$ gen & & & \\
\hline Native $=2$ gen $>1$ gen & 0 & + & +1 \\
\hline 2gen > Native > 1gen & - & + & +1 \\
\hline 1gen > Native > 2gen & + & - & -1 \\
\hline 2gen $>$ Native $=1$ gen & & & \\
\hline 1gen $>$ Native $=2$ gen & 0 & - & -1 \\
\hline 1gen $=2$ gen $>$ Native & - & 0 & -1 \\
\hline 1gen $>$ 2gen $>$ Native & - & - & -1 \\
\hline 2gen > 1gen > Native & - & - & -1 \\
\hline Native $=2$ gen $=1$ gen & & & \\
\hline
\end{tabular}
difference in callback rates
Table 3.

Direction of the TBDI, SDI and DDI, based on the comparison between the callback rates obtained by each category of candidates 
IJSE

47,12

callback by a company. If $Y^{*}>0$, the corresponding observed dummy variable, $Y$, is equal to 1 (Call-back: Yes $=1$ ); if $Y^{*}=0$, the corresponding value of the dummy variable $Y$ is 0 (Callback: No $=0$ ). On the right side of the equation, Greek letters refer to parameters. Namely, $\beta_{0}$ is the constant term and $\varepsilon$ is the disturbance term. The main explanatory variables are the sex of the subject (Woman: $1=$ yes; $0=$ Man), the education level of the subject, corresponding to the education required by the job opening (Graduate: $1=$ yes, 0 = otherwise; High School: 1 = yes, 0 = otherwise; reference: No title), job characteristics (Front Office: 1 = yes, 0 = Back Office; Hard Work: $1=$ yes, 0 = Soft work). Considering also the North-South territorial gaps in the employment rates - employment rates in the southern part of Italy are at $42.5 \%$ versus an average of $64.8 \%$ in the northern regions (Istat, 2016) - we add two geographical variables: the geographical area of the firm (North-Centre $=1$; South and Islands $=0$ ) and the employment rate at regional level (employment rate). FirstGen and SecondGen are two dummy variables regarding the ethnicity of the candidate (FirstGen: $1=$ the candidate is immigrant of first generation, $0=$ otherwise; SecondGen: $1=$ the candidate is immigrant of second generation, $0=$ otherwise).

To focus on the importance of the potential ethnic discrimination in the Italian labour market, we also estimated four probit models including interaction terms between several variables (such as job characteristics, education required and the sex of the subject) and firstand second-generation dummy variables and then ran the probit model A at a greater level of detail, showing the coefficients for each different immigrants' nationality (see Table 6). The theory behind marginal effects and interaction terms is explained in the Appendix.

\section{Results}

Our results confirm that the situation in the Italian labour market is more favourable to second-generation candidates compared to first-generation ones, even though the former still experience disadvantages compared to their native peers (Heath et al., 2008). Moreover, our results always show a positive total discrimination, as the majority group (Italian) is always preferred over the two minority ones (first and second generation).

In particular, the interesting result is that the level of discrimination associated with tastebased reasons is quantitatively huge, accounting for most of the total discrimination, while statistical discrimination is not so massive (Table 4).

It seems that employers, rather than considering second-generation candidates as substitutes for Italian candidates, consider them as substitutes for first-generation candidates. In general, the TBDI is equal to 0.703 , while the SDI is 0.297 . A very high level of taste-based discrimination is economically unsafe, being incompatible with firms' profitmaximising behaviour (Becker, 1971).

Moreover, taste-based discrimination is higher for women (0.731) than for men (0.675), as discrimination based on gender sums with the one connected to the level of nativeness (i.e. Italians, first- and second-generation immigrants).

Taste-based discrimination is lower for jobs requiring customer contact $(0.623)$ than for back office ones (0.796), due to the fact that second- and first-generation candidates are called back with similar rates for jobs belonging to the last category.

Taste-based discrimination is higher for graduates (0.654) compared to high school candidates (0.606). This result is particularly worrying, as it makes it less convenient for second-generation immigrants compared to their native peers to invest in higher education. For jobs not requiring any qualification, the SDI is close to zero, as the difference in callback rates between first- and second-generation candidates is very small.

Comparing the level of discrimination between Italian North-Centre and South-Islands, we observe that taste-based discrimination is massively huger in the former than in the latter, meaning that racism is more widespread in the northern part of the country than in the South. 


\begin{tabular}{|c|c|c|c|c|c|c|c|}
\hline & \multirow[b]{2}{*}{$\begin{array}{c}\text { Italian } \\
\mathrm{A}\end{array}$} & \multicolumn{2}{|c|}{ Call-back rates } & \multicolumn{2}{|c|}{ DDI } & \multirow[b]{2}{*}{$\begin{array}{c}\text { Total } \\
\text { discrimination } \\
\end{array}$} & \multirow{2}{*}{$\begin{array}{l}\text { The } \\
\text { discrimination } \\
\text { decomposition }\end{array}$} \\
\hline & & $\begin{array}{c}\text { First } \\
\text { generation B }\end{array}$ & $\begin{array}{c}\text { Second } \\
\text { generation C }\end{array}$ & TBDI $=\frac{A-C}{|A-B|}$ & $\mathrm{SDI}=\frac{C-B}{|A-B|}$ & & \\
\hline Total & 0.118 & 0.054 & 0.073 & 0.703 & 0.297 & +1 & $\mathrm{X}$ \\
\hline Woman & 0.092 & 0.040 & 0.054 & 0.731 & 0.269 & +1 & \\
\hline Man & 0.145 & 0.068 & 0.093 & 0.675 & 0.325 & +1 & \\
\hline $\begin{array}{l}\text { Front } \\
\text { office }\end{array}$ & 0.116 & 0.039 & 0.068 & 0.623 & 0.377 & +1 & 1587 \\
\hline Back office & 0.121 & 0.067 & 0.078 & 0.796 & 0.204 & +1 & \\
\hline Hard work & 0.079 & 0.059 & 0.053 & 1.300 & -0.300 & +1 & \\
\hline Soft work & 0.136 & 0.052 & 0.082 & 0.643 & 0.357 & +1 & \\
\hline Graduate & 0.136 & 0.058 & 0.085 & 0.654 & 0.346 & +1 & \\
\hline $\begin{array}{l}\text { High } \\
\text { school }\end{array}$ & 0.118 & 0.052 & 0.078 & 0.606 & 0.394 & +1 & \\
\hline No title & 0.107 & 0.054 & 0.059 & 0.906 & 0.094 & +1 & \\
\hline $\begin{array}{l}\text { North- } \\
\text { Centre }\end{array}$ & 0.130 & 0.062 & 0.080 & 0.735 & 0.265 & +1 & $\begin{array}{r}\text { Table } 4 . \\
\text { Callback rates and }\end{array}$ \\
\hline $\begin{array}{l}\text { South- } \\
\text { Islands }\end{array}$ & 0.081 & 0.027 & 0.052 & 0.537 & 0.463 & +1 & $\begin{array}{r}\text { discrimination } \\
\text { decomposition index }\end{array}$ \\
\hline
\end{tabular}

This situation may be explained by the fact that political movements against migrants are more widespread in the North compared to the other parts of Italy. It would also be interesting to control for the recruiters' socio-economic individual characteristics; unfortunately, this information is not available as search engines do not provide it. Nevertheless, we assume that recruiters' behaviour, regardless of their own characteristics and opinions, will be in line with the average political alignment of the region in which the firm is located.

Only for hard-work jobs, the SDI assumes a negative value, meaning that firstgeneration immigrants are preferred over second-generation ones. A possible reason for this apparently strange result is that, for a large share of hard-work jobs, first-generation candidates were the only ones being called back; most probably, this is because interviewers prefer to hire the most disadvantaged candidates, as they are the ones with the lowest probability of obtaining another job in the Italian labour market.

In addition, we calculated the DDI for the different nationalities and job characteristics. The full results are shown in Table 5. First-generation immigrants of all nationalities but Germans, which are indeed not considered a disadvantaged nationality, are preferred for hard-work jobs.

To test whether the probability of obtaining a job interview is statistically different between the various categories of candidates and jobs, we estimated six probit models (FULL, A, B, C, D and E), in which the following variables are included: area, gender, ethnicity, employment rate, level of education, degree of vis a vis contact with the public and physical strength required by the job. Probit estimations are reported in Table 6 . In the first column (FULL), we show the results of the model using the full sample. In the other columns (Models A-E), we show the model applied after restricting the sample to the companies that replied to at least one résumé. While the models FULL and A include the same covariates, models from $\mathrm{B}$ to $\mathrm{E}$ furtherly include the interaction effect of several variables such as job characteristics, required education level, gender and ethnicity. Coefficients maintain the same sign in every model. After restricting the sample, the impact of the covariates remained almost the same, becoming even more marked in some cases and revealing a good level of robustness (see Table 6). 


\begin{tabular}{|c|c|c|c|c|c|c|c|c|c|c|c|}
\hline \multirow{2}{*}{$\begin{array}{l}\text { 1JSE } \\
47,12\end{array}$} & & \multicolumn{2}{|c|}{ Albanians } & \multicolumn{2}{|c|}{ Chinese } & \multicolumn{2}{|c|}{ Germans } & \multicolumn{2}{|c|}{ Moroccans } & \multicolumn{2}{|c|}{ Romanians } \\
\hline & & TBDI & SDI & TBDI & SDI & TBDI & SDI & TBDI & SDI & TBDI & SDI \\
\hline \multirow{6}{*}{1588} & Total & 0.625 & 0.375 & 0.806 & 0.194 & 0.533 & 0.467 & 0.786 & 0.214 & 0.702 & 0.298 \\
\hline & $v_{r}$ & 0.636 & 0.364 & 0.818 & 0.182 & 0.652 & 0.348 & 0.774 & 0.226 & 0.760 & 0.240 \\
\hline & Man & 0.617 & 0.383 & 0.797 & 0.203 & 0.441 & 0.559 & 0.793 & 0.207 & 0.667 & 0.333 \\
\hline & Front office & 0.540 & 0.460 & 0.747 & 0.253 & 0.483 & 0.517 & 0.716 & 0.284 & 0.598 & 0.402 \\
\hline & Back office & 0.734 & 0.266 & 0.882 & 0.118 & 0.592 & 0.408 & 0.865 & 0.135 & 0.831 & 0.169 \\
\hline & Hard work & 1.139 & -0.139 & 1.426 & -0.426 & 0.885 & 0.115 & 1.402 & -0.402 & 1.852 & -0.852 \\
\hline \multirow{7}{*}{$\begin{array}{l}\text { Table } 5 \text {. } \\
\text { Callback rates and } \\
\text { discrimination } \\
\text { decomposition index } \\
\text { by nationality }\end{array}$} & Sof & 0.597 & 0.403 & 0.734 & 0.266 & 0.499 & 0.501 & 0.739 & 0.261 & 0.638 & 0.362 \\
\hline & Gradu & 0.571 & 0.429 & 0.816 & 0.184 & 0.333 & 0.667 & 0.893 & 0.107 & 0.615 & 0.385 \\
\hline & High school & 0.532 & 0.468 & 0.710 & 0.290 & 0.488 & 0.512 & 0.662 & 0.338 & 0.611 & 0.389 \\
\hline & No title & 0.875 & 0.125 & 0.926 & 0.074 & 0.801 & 0.199 & 0.895 & 0.105 & 0.970 & 0.030 \\
\hline & No & 0.679 & 0.321 & 0.813 & 0.187 & 0.602 & 0.398 & 0.814 & 0.186 & 0.762 & 0.238 \\
\hline & South-Islands & 0.407 & 0.593 & 0.778 & 0.222 & 0.178 & 0.822 & 0.666 & 0.334 & 0.461 & 0.539 \\
\hline & $T$ & & & & & cate & & ona & & & \\
\hline
\end{tabular}

Figure 3.

Average marginal effects of general model A
A relevant and statistically significant discrimination can be pointed out against women and immigrants of both first and second generation. In this respect, first-generation candidates seem to be more discriminated than second-generation ones, but the difference between the two categories, even if relevant, does not seem to be massive. As suggested by Ai and Norton (2003), to test the statistical significance of interacted variables, it is necessary to estimate the cross-partial derivative. For this reason, we calculated the average marginal effects for all the dummy variables in our models (Table 7). In Figure 3, we report the average marginal effects only for the first model.

Looking at the marginal effects, the robustness of the different models proposed is also confirmed. Indeed, they maintain same sign, significance and similar values in all of the five models proposed (Models A-E). In all models, the probability of obtaining an interview when applying to a job offer in the North-Centre is 12 percentage points higher with respect to South and Islands. On the other side, it is 15 percentage points lower for female candidates than for men. In terms of education, applying for jobs requiring graduation produces an increase in callback rates of almost 6 percentage points with respect to jobs requiring no title,

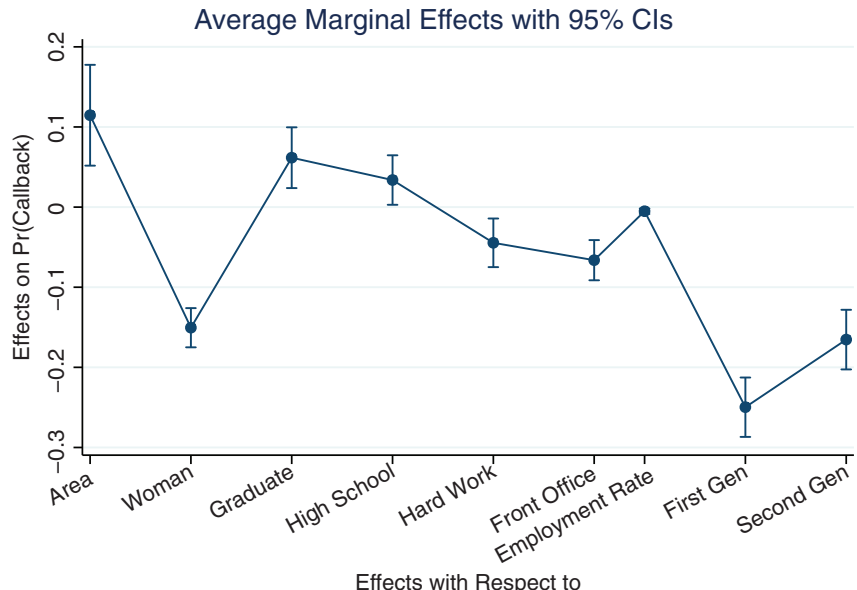




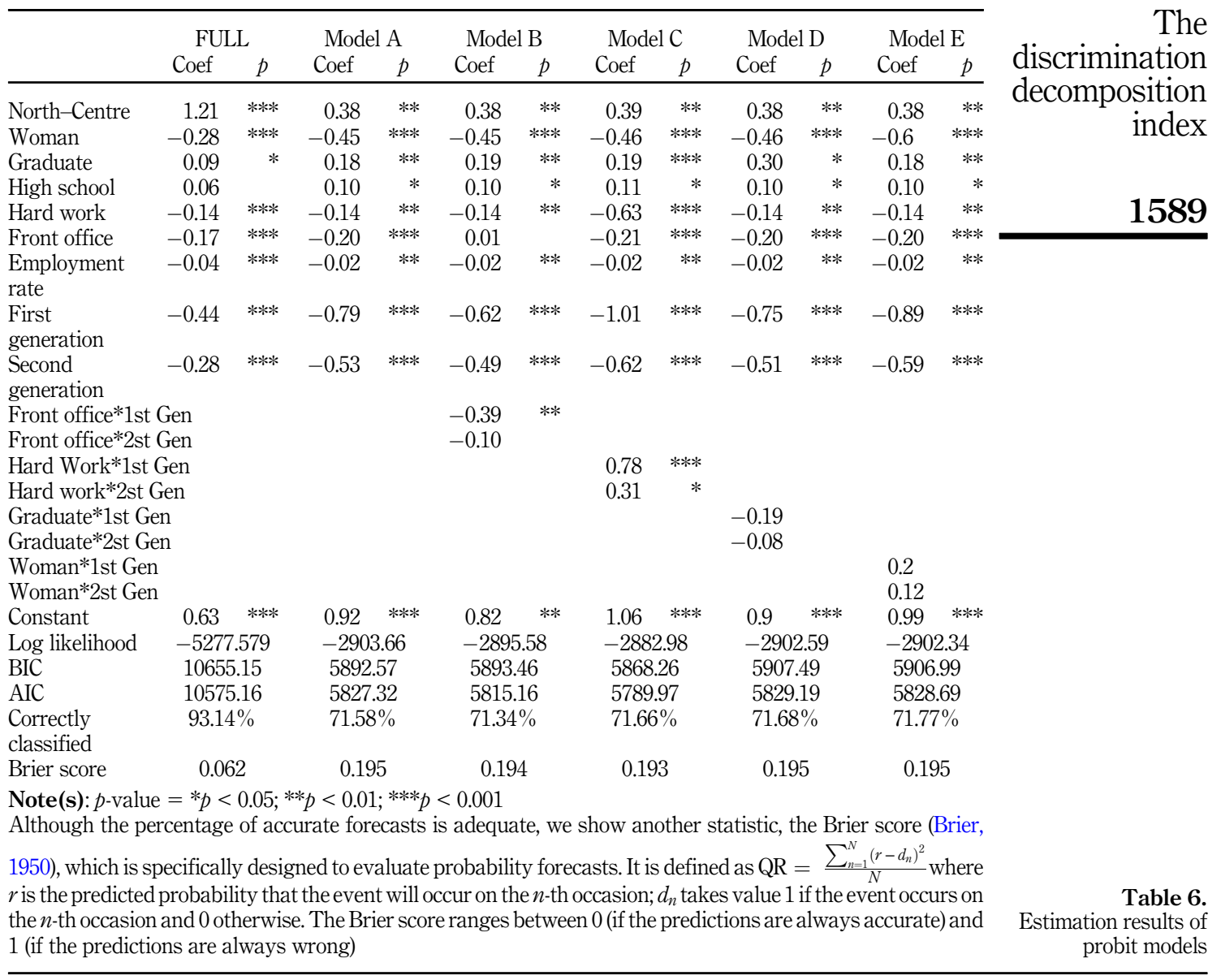

while applying for jobs requiring high school diploma makes them rise by almost 3 percentage points. Regarding the type of job, applying for a front office one produces a decrease in callback rates by almost 7 percentage points with respect to back office; for hardwork jobs, with respect to soft work, by almost 5 percentage points.

With respect to Italians, if the candidate is a first-generation immigrant, the probability decreases by almost 25 percentage points, while if he/she is a second-generation one, it decreases by 17 percentage points.

Predictive margins of the interaction terms are shown in Table 8.

Considering the characteristics of the jobs, we can observe that the difference between front and back office is relevant for both generations, and both are in favour of back office jobs. Callback rates for these jobs are $22 \%$ if the candidate is a first-generation immigrant and $25 \%$ if he/she is a second-generation one. The difference between candidates of first and second generation increases by 7 percentage points if the job is a front office one.

While differences in callback rates between hard and soft work are not considerably different for the second generation $-22 \%$ and $23 \%$, respectively - they become massive for the first generation with a percentage of $23 \%$ and $16 \%$, respectively. Moreover, foreign 
IJSE

47,12

1590 candidates, with respect to Italians, are always favoured when applying to hard-work positions.

The third interaction term that we considered concerns level of education required and the generation variable. For first-generation immigrants, a higher level of education does not increase the probability of being called back by firms, confirming that education level does not reduce the penalty for first-generation immigrants (Fullin and Reyneri, 2011). The situation changes for second-generation immigrants. In fact, for this subsample the probability increases by 4 percentage points (from $22 \%$ to $26 \%$ ).

Furthermore, we considered the interaction effects between gender and ethnicity. Regarding gender difference in callback rates, from the probit estimation results (see Table 6)
Table 7.

Estimation results of probit average marginal effects

\begin{tabular}{|c|c|c|c|c|c|c|c|c|c|c|}
\hline & \multicolumn{2}{|c|}{ Model A } & \multicolumn{2}{|c|}{ Model B } & \multicolumn{2}{|c|}{ Model C } & \multicolumn{2}{|c|}{ Model D } & \multicolumn{2}{|c|}{ Model E } \\
\hline & $\mathrm{dy} / \mathrm{dx}$ & $p$ & $\mathrm{dy} / \mathrm{dx}$ & $p$ & $\mathrm{dy} / \mathrm{dx}$ & $p$ & $\mathrm{dy} / \mathrm{dx}$ & $p$ & $\mathrm{dy} / \mathrm{dx}$ & $p$ \\
\hline Centre & 0.115 & $* * *$ & 0.114 & $* * *$ & 0.116 & $* * *$ & 0.115 & $* * *$ & 0.114 & \\
\hline Woman & -0.151 & $* * *$ & -0.150 & $* * *$ & -0.150 & $* * *$ & -0.151 & $* * *$ & -0.151 & \\
\hline Graduate & 0.062 & $* *$ & 0.062 & $* *$ & 0.063 & $* *$ & 0.062 & $* *$ & 0.062 & \\
\hline High school & 0.034 & $*$ & 0.034 & $*$ & 0.034 & $*$ & 0.034 & $*$ & 0.034 & \\
\hline Front office & -0.066 & $* * *$ & -0.065 & $* * *$ & -0.066 & $* * *$ & -0.066 & $* * *$ & -0.066 & \\
\hline Hard work & -0.045 & $* *$ & -0.044 & $* *$ & -0.046 & $* *$ & -0.045 & $* *$ & -0.045 & \\
\hline First generation & -0.250 & $* * *$ & -0.247 & $* * *$ & -0.248 & $* * *$ & -0.250 & $* * *$ & -0.252 & \\
\hline Second generation & -0.165 & $* * *$ & -0.164 & $* * *$ & -0.163 & $* * *$ & -0.166 & $* * *$ & -0.167 & \\
\hline
\end{tabular}

Note(s): $p$-value $=* p<0.05 ; * * p 0.01 ; * * * p<0.001$. Only dummy covariates are considered

\begin{tabular}{|c|c|c|c|c|c|c|c|c|}
\hline & & el B & & lel C & & el D & $\mathrm{M}$ & el E \\
\hline & $\mathrm{dy} / \mathrm{dx}$ & Std. err & $\mathrm{dy} / \mathrm{dx}$ & Std. err & $\mathrm{dy} / \mathrm{dx}$ & Std. err & $\mathrm{dy} / \mathrm{dx}$ & Std. err \\
\hline First generation & 0.18 & 0.01 & 0.18 & 0.01 & 0.18 & 0.01 & 0.18 & 0.01 \\
\hline Second generation & 0.23 & 0.01 & 0.23 & 0.01 & 0.22 & 0.01 & 0.22 & 0.01 \\
\hline Back office & 0.33 & 0.01 & & & & & & \\
\hline Front office & 0.26 & 0.01 & & & & & & \\
\hline Back office*1st gen & 0.22 & 0.01 & & & & & & \\
\hline Front office*1st gen & 0.13 & 0.01 & & & & & & \\
\hline Back office*2nd gen & 0.25 & 0.01 & & & & & & \\
\hline Front office*2nd gen & 0.20 & 0.01 & & & & & & \\
\hline Soft work & & & 0.31 & 0.01 & & & & \\
\hline Hard work & & & 0.27 & 0.01 & & & & \\
\hline Soft work*1st gen & & & 0.16 & 0.01 & & & & \\
\hline Hard work*1st gen & & & 0.23 & 0.02 & & & & \\
\hline Soft work*2nd gen & & & 0.23 & 0.01 & & & & \\
\hline Hard work*2nd gen & & & 0.22 & 0.02 & & & & \\
\hline Graduate & & & & & 0.35 & 0.02 & & \\
\hline Graduate*1st gen & & & & & 0.19 & 0.02 & & \\
\hline Graduate*2nd gen & & & & & 0.26 & 0.02 & & \\
\hline Man & & & & & & & 0.38 & 0.01 \\
\hline Woman & & & & & & & 0.22 & 0.01 \\
\hline Man*1st gen & & & & & & & 0.22 & 0.01 \\
\hline Woman*1st gen & & & & & & & 0.13 & 0.01 \\
\hline Man*2nd gen & & & & & & & 0.28 & 0.01 \\
\hline Woman*2nd gen & & & & & & & 0.17 & 0.01 \\
\hline Note(s): $p$-values not & rte & ey at & 001 in $\mathrm{c}$ & ases & & & & \\
\hline
\end{tabular}

Table 8.

Predictive margins of the interaction terms 
a huge penalty paid by women emerges, in both cases of natives and immigrants. Considering women in general (see Table 8), the probability is equal to $22 \%$, while it is $38 \%$ for men. This probability decreases if we consider only immigrant women, with respect to native ones. Deeply, callback rates are equal to $13 \%$ for first-generation immigrant women ( $22 \%$ for men) and to $17 \%$ if the candidate is a second-generation woman (28\% if man). Finally, for the sake of completeness, we ran the probit model A at a greater level of detail, showing the coefficients for each different immigrants' nationality in Table 9.

\section{Conclusions}

Following the major field experiments on labour market discrimination based on ethnicity (for a review, see Rich, 2014; Baert, 2018; Lippens et al., 2020) and, in particular, a recent application to Italy (Busetta et al., 2018), this study extends the previous results, by introducing the DDI to split total discrimination into its statistical and taste-based components.

As discrimination based on nationality in labour markets could be driven by reasons connected to differences in productivity (such as education and language gaps) for firstgeneration candidates, the same cannot be said about second-generation ones, who are Italian citizens in every respect. Indeed, in our experiment, all second-generation immigrants are of Italian mother tongue and attended Italian schools and universities: therefore, discrimination against second-generation candidates can only be connected to racism (taste-based discrimination). Consequently, our idea is to split these two different discrimination components, dividing immigrants into first- and second-generation ones.

The most relevant results show the presence of significant discrimination against immigrants of both first and second generation. In this respect, the probit estimation results show that first-generation candidates are more discriminated than second-generation ones, but the difference between the two categories does not seem to be massive. This result appears to be impressive, and it maintains consistency even when considering the different characteristics of the jobs. This result is in line with Carlsson (2010), who found that first- and second-generation immigrants had very similar callback rates, suggesting that minority groups with a Middle Eastern background are largely discriminated against because of their

\begin{tabular}{|c|c|c|c|c|c|c|c|c|c|c|}
\hline & \multicolumn{2}{|c|}{ Albanians } & \multicolumn{2}{|c|}{ Chinese } & \multicolumn{2}{|c|}{ Germans } & \multicolumn{2}{|c|}{ Moroccans } & \multicolumn{2}{|c|}{ Romanians } \\
\hline & Coef & $p$ & Coef & $p$ & Coef & $p$ & Coef & $p$ & Coef & $p$ \\
\hline North-Centre & 0.46 & $*$ & 0.44 & $*$ & -0.07 & & 0.42 & & 0.51 & * \\
\hline Woman & -0.50 & $* * *$ & -0.51 & $* * *$ & -0.60 & $* * *$ & -0.42 & $* * *$ & -0.47 & $* * *$ \\
\hline Graduate & 0.10 & & 0.16 & & 0.17 & & 0.15 & & 0.15 & \\
\hline High school & 0.02 & & 0.12 & & 0.04 & & 0.04 & & 0.04 & \\
\hline Hard work & -0.23 & $*$ & -0.38 & $* * *$ & -0.38 & $* * *$ & -0.22 & $*$ & -0.25 & $* *$ \\
\hline Front office & -0.18 & $*$ & -0.25 & $* *$ & -0.11 & & -0.15 & & -0.16 & $*$ \\
\hline Employment rate & -0.02 & $*$ & -0.01 & & 0.00 & & -0.02 & & -0.02 & * \\
\hline First generation & -0.84 & $* * *$ & -0.84 & $* * *$ & -0.64 & $* * *$ & -0.87 & $* * *$ & -0.80 & $* * *$ \\
\hline $\begin{array}{l}\text { Second } \\
\text { generation }\end{array}$ & -0.50 & $* * *$ & -0.66 & $* * *$ & -0.33 & $* * *$ & -0.65 & $* * *$ & -0.54 & $* * *$ \\
\hline Constant & 1.32 & $* *$ & 0.86 & & 0.57 & & 0.98 & $*$ & 1.36 & $* *$ \\
\hline Log likelihood & -817.568 & & -791.110 & & -847.285 & & -799.383 & & -819.072 & \\
\hline $\mathrm{BIC}$ & 1707.392 & & 1654.476 & & 1766.825 & & 1671.022 & & 1710.399 & \\
\hline AIC & 1655.137 & & 1602.221 & & 1714.57 & & 1618.767 & & 1658.145 & \\
\hline $\begin{array}{l}\text { Correctly } \\
\text { classified }\end{array}$ & $68.85 \%$ & & $69.72 \%$ & & $66.52 \%$ & & $70.82 \%$ & & $69.43 \%$ & \\
\hline Brier score & 0.204 & & 0.195 & & 0.214 & & 0.197 & & 0.204 & \\
\hline
\end{tabular}

Note(s): $p$-value $=* p<0.05 ; * * p<0.01 ; * * * p<0.001$ discrimination decomposition index

1591
Estimation Table probit models by nationality 
IJSE

47,12 ethnicity per se and not because of their country of birth, mother tongue and foreign education.

Our results are confirmed by the DDI, which highlights the higher share of taste-based discrimination compared to the statistical one. Indeed, the difference between front and back office is relevant for both generations and in favour of back office jobs. A higher probability of obtaining a job interview emerges for candidates applying in North-Centre, compared to South of Italy. Employment rate is characterised by a negative and statistically significant coefficient, meaning that, if the job offer comes from an area characterised by a more dynamic - and competitive - labour market, the probability of being called back decreases. Furthermore, also taste-based discrimination appears to be higher for North-Centre than for South of Italy, meaning that the behaviour of recruiters is characterised by a higher level of racism in the former area than in the latter.

On the one hand, Education shows a higher statistically significant increase in callback rates for high-qualified job offers, meaning that it is easier to get a job interview for highly qualified candidates. On the other hand, taste-based discrimination increases for graduates $(65.4 \%)$ with respect to high school candidates $(60.6 \%)$, making it less convenient for secondgeneration immigrants to invest in higher education compared to natives.

Both the front office and hard-work components of the job offer decrease the chance of getting a job interview. Deeply, all the concerning coefficients maintain the same sign and statistical significance in all the analysed models, revealing a good level of robustness.

Only for hard-work jobs, the SDI assumes a negative value, meaning that firstgeneration immigrants are preferred over second-generation ones, most probably because interviewers prefer to hire the most disadvantaged candidates, as they are characterised by the lowest probability of obtaining another job in the Italian labour market. This is in line with the dual labour market theory, according to which the job market is composed of two segments (Doeringer and Piore, 1985; Piore, 1979). In the first segment - referred to soft-work jobs - workers generally receive relatively high wages and have stable jobs, while in the second segment - pertaining to hard-work jobs - they get relatively low wages, working in more unstable jobs with a higher probability of changing their job. The low bargaining power of first-generation immigrants makes their job-switch probability smaller, so that employers become more likely to call them back for a job interview.

Discrimination against disadvantaged groups in the labour market is a major problem affecting many countries. Several nations already provide policy measures that aim at promoting the education and employment of non-dominant socio-political groups, usually minorities or women. These tools are known as "affirmative action". For example, in the United States of America, preferential treatment for people belonging to disadvantaged groups has existed for almost 60 years: in 1961, President Kennedy signed Executive Order 10925, which abolishes racial discrimination in the public sector, providing affirmative action policies to ensure that candidates are recruited and treated without distinction based on criteria of race, caste, provenance or skin colour. Nevertheless, Hitt et al. (1982) demonstrated that affirmative action had not produced relevant results, and we have no evidence to say that this situation has changed up to now.

Italy has unfortunately not implemented any corrective measures to fight the effects of racial discrimination in the labour market. In light of the results of this paper, introducing such corrective measures in Italy appears to be particularly relevant because a massive part of discrimination against immigrants in the Italian labour market concerns the taste-based one, which is incompatible with firms' profit-maximising behaviour (Becker, 1971).

The solution could be to adopt targeted recruitment programmes and preferential treatment for disadvantaged socio-political groups, such as the use of a quota system within companies, whereby a certain percentage of jobs would be reserved to immigrants. Deeply, 
the results coming from our DDI suggest addressing such programmes specifically to secondgeneration immigrants.

\section{References}

Ai, C. and Norton, E.C. (2003), "Interaction terms in logit and probit models", Economics Letters, Vol. 80, pp. 123-129.

Altonji, J.G. and Pierret, C.R. (2001), "Employer learning and statistical discrimination", Quarterly Journal of Economics, Vol. 464 No. 1, pp. 313-50.

Andriessen, I., Nievers, E., Faulk, L. and Dagevos, J. (2010), Do Employers Prefer Mark over Mohammed?, Sociaal en Cultureel Planbureau, The Hague.

Arai, M., Bursell, M. and Nekby, L. (2016), "The reverse gender gap in ethnic discrimination: employer stereotypes of men and women with Arabic names", International Migration Review, Vol. 50 No. 2, pp. 385-412.

Arrow, K.J. (1972), "Model of job discrimination", in Pascal, A.H. (Ed.), Racial Discrimination in Economic Life, Lexington Books, Lexington, MA.

Arrow, K.J. (1973), "The theory of discrimination", in Ashenfelter, O. and Rees, A. (Eds), Discrimination in Labour Markets, Princeton University Press, Princeton, pp. 3-33.

Baert, S. (2018), "Hiring discrimination: an overview of (almost) all correspondence experiments since 2005”, Audit Studies: Behind the Scenes with Theory, Method, and Nuance, Springer, Cham, pp. 63-77.

Bauer, T., Lofstrom, M. and Zimmermann, K.F. (2000), "Immigration policy, assimilation of immigrants, and natives' sentiments towards immigrants: evidence from 12 OECD countries", Swedish Economic Policy Review, Vol. 7, pp. 11-53.

Becker, G.S. (1971), The Economics of Discrimination, The University of Chicago Press, Chicago.

Bertrand, M. and Mullainathan, S. (2004), "Are Emily and Greg more employable than Lakisha and Jamal? A field experiment on labour market discrimination”, American Economic Review, Vol. 94, pp. 991-1013.

Brier, G.W. (1950), "Verification of weather forecasts expressed in terms of probability", Monthly Weather Review, Vol. 78, pp. 1-3.

Bursell, M. (2007), What's in a Name? A Field Experiment Test for the Existence of Ethnic Discrimination in the Hiring Process, Working Paper, Vol. 7, Stockholm University Linnaeus Center for Integration Studies (SULCIS), pp. 1-28.

Bursell, M. (2014), "The multiple burdens of foreign-named men - evidence from a field experiment on gendered ethnic hiring discrimination in Sweden”, European Sociological Review, Vol. 30, pp. 399-409.

Busetta, G., Campolo, M.G. and Panarello, D. (2018), "Immigrants and Italian labor market: statistical or taste-based discrimination?", Genus, Vol. 74 No. 4, pp. 1-20.

Busetta, G., Campolo, M.G. and Panarello, D. (2020a), "Weight-based discrimination in the Italian Labor Market: an analysis of the interaction with gender and ethnicity", The Journal of Economic Inequality, pp. 1-21, doi: 10.1007/s10888-020-09456-5.

Busetta, G., Fiorillo, F. and Palomba, G. (2020b), "The impact of attractiveness on job opportunities in Italy: a gender field experiment", Economia Politica, pp. 1-31, doi: 10.1007/s40888-020-00194-5.

Bygren, M., Erlandsson, A. and Gähler, M. (2017), "Do employers prefer fathers? Evidence from a field experiment testing the gender by parenthood interaction effect on callbacks to job applications”, European Sociological Review, Vol. 33 No. 3, pp. 337-348.

Carlsson, M. (2010), "Experimental evidence of discrimination in the hiring of first- and secondgeneration immigrants", Labour, Vol. 24 No. 3, pp. 263-278. 
IJSE

47,12

1594

Chen, Y.P.V. and Zhang, Y. (2018), “A decomposition method on employment and wage discrimination and its application in urban China (2002-2013)", World Development, Vol. 110, pp. 1-12.

Cross, H., Kenney, G., Mell, J. and Zimmerman, W. (1990), Employer Hiring Practices: Differential Treatment of Hispanic and Anglo Job Seekers, Urban Institute Press, Washington DC.

Doeringer, P. and Piore, M. (1985), Internal Labor Markets and Manpower Analysis, ME Sharpe, London.

Drydakis, N. (2009), "Sexual orientation discrimination in the labour market", Labour Economics, Vol. 16 No. 4, pp. 364-372.

Duncan, O.D. and Duncan, B. (1955), “A methodological analysis of segregation indexes”, American Sociological Review, Vol. 20 No. 2, pp. 210-217.

Evans, W. (2012), "Eye-tracking online metacognition: cognitive complexity and recruiter decision making", available at: http://www.bu.edu/com/files/2018/10/TheLadders-EyeTracking-StudyC2. pdf (accessed 23 November 2019).

Fullin, G. and Reyneri, E. (2011), "Low unemployment and bad jobs for new immigrants in Italy", International Migration, Vol. 49, pp. 118-147.

Giacalone, M., Mattera, R. and Panarello, D. (2019), "Education and migration: the mobility dynamics of Italian graduates", Statistica Applicata-Italian Journal of Applied Statistics, Vol. 31 No. 1, pp. 143-156.

Glitz, A. (2014), "Ethnic segregation in Germany", Labour Economics, Vol. 29, pp. $28-40$.

Greene, W.H. (2003), Econometric Analysis, Prentice Hall, Upper Saddle River, NJ.

Heath, A.F., Rothon, C. and Kilpi, E. (2008), "The second generation in Western Europe: education, unemployment, and occupational attainment”, Annual Review of Sociology, Vol. 34, pp. 211-235.

Hitt, M.A., Zikmund, W.G. and Pickens, B.A. (1982), "Discrimination in industrial employment: an investigation of race and sex bias among professionals", Work and Occupations, Vol. 9 No. 2, pp. 217-231.

Istat (2013), "La popolazione straniera residente in Italia - Bilancio demografico. Anno 2012", available at: http://www.istat.it/it/files/2013/07/BilancioDemograficoStranieri_2012.pdf?title= Stranieri+residenti+in+Italia+-+26\%2Flug\%2F2013+-+Testo+integrale.pdf (accessed 13 September 2019).

Istat (2015), "L'integrazione degli stranieri e dei naturalizzati nel mercato del lavoro. II trimestre 2014", available at: http:/www.istat.it/it/files/2015/12/Lavoro_stranieri.pdf?title=Integrazione+degli+ stranieri+nel+lavoro++-+28\%2Fdic $\% 2 \mathrm{~F} 2015+-+$ Testo+integrale+e+nota+integrale.pdf (accessed 13 September 2019).

Istat (2016), "Le dinamiche del mercato del lavoro: una lettura per generazione", in Rapporto Annuale, available at: http://www.istat.it/it/files/2016/04/Cap_3_Ra2016.pdf (accessed 14 September 2019).

Kaas, L. and Manger, C. (2012), "Ethnic discrimination in Germany's labour market: a field experiment", German Economic Review, Vol. 13, pp. 1-20.

Knowles, J., Persico, N. and Todd, P. (2001), "Racial bias in motor vehicle searches: theory and evidence", Journal of Political Economy, Vol. 109 No. 1, pp. 203-29.

Lahey, J.N. (2008), "Age, women, and hiring: an experimental study", Journal of Human Resources, Vol. 43, pp. 30-56.

Lippens, L., Baert, S., Ghekiere, A., Verhaeghe, P.P. and Derous, E. (2020), "Is labour market discrimination against ethnic minorities better explained by taste or statistics? A systematic review of the empirical evidence", Institute for the Study of Labour, IZA Discussion Paper No. 13523, pp. 1-54.

Midtbøen, A.H. (2016), "Discrimination of the second generation: evidence from a field experiment in Norway", Journal of International Migration and Integration, Vol. 17 No. 1, pp. 253-272. 
Neumark, D. (2004), Sex Differences in Labor Markets, Routledge, London.

Norton, E.C., Wang, H. and Ai, C. (2004), "Computing interaction effects and standard errors in logit and probit models", Stata Journal, Vol. 4, pp. 154-167.

Nunley, J.M., Pugh, A., Romero, N. and Seals, R.A. (2015), "An examination of racial discrimination in the labour market for recent college graduates: estimates from the field", The BE Journal of Economic Analysis and Policy, Vol. 15 No. 3, pp. 1093-1125.

Olian, J.D., Schwab, D.P. and Haberfeld, Y. (1988), "The impact of applicant gender compared to qualifications on hiring recommendations: a meta-analysis of experimental studies", Organizational Behavior and Human Decision Processes, Vol. 41 No. 2, pp. 180-195.

Oreopoulos, P. (2011), "Why do skilled immigrants struggle in the labour market? A field experiment with thirteen thousand resumes", American Economic Journal: Economic Policy, Vol. 3 No. 4, pp. 148-171.

Orrenius, P.M. and Zavodny, M. (2009), "Do immigrants work in riskier jobs?”, Demography, Vol. 46 No. 3, pp. 535-551.

Phelps, E.S. (1972), "The statistical theory of racism and sexism", The American Economic Review, Vol. 62 No. 4, pp. 659-661.

Piore, M. (1979), Birds of Passage. Migrant Labor and Industrial Societies, Cambridge University Press, Cambridge.

Quintano, C., Mazzocchi, P. and Rocca, A. (2019), "Immigrants in the EU5 labour markets: what happened during the economic crisis?", International Journal of Manpower, Vol. 41 No. 1, pp. 68-83.

Raijman, R. and Semyonov, M. (1997), "Gender, ethnicity, and immigration: double disadvantage and triple disadvantage among recent immigrant women in the Israeli labor market", Gender and Society, Vol. 11 No. 1, pp. 108-125.

Riach, P.A. and Rich, J. (1991), "Testing for racial discrimination in the labour market", Cambridge Journal of Economics, Vol. 15 No. 3, pp. 239-256.

Riach, P.A. and Rich, J. (2002), "Field experiments of discrimination in the market place", The Economic Journal, Vol. 112 No. 483, pp. F480-F518.

Riach, P.A. and Rich, J. (2004), "Deceptive field experiments of discrimination: are they ethical?", Kyklos, Vol. 57, pp. 457-470.

Rich, J. (2014), "What do field experiments of discrimination in markets tell us? A meta-analysis of studies conducted since 2000", Institute for the Study of Labour, IZA Discussion Paper No. 8584, pp. 1-68.

Riva, E. and Zanfrini, L. (2013), "The labour market condition of immigrants in Italy: the case of Lombardy", Revue Interventions Économiques, Vol. 47, pp. 1-27.

Rooth, D.O. (2009), "Obesity, attractiveness, and differential treatment in hiring", Journal of Human Resources, Vol. 44 No. 3, pp. 710-735.

Saraceno, C., Sartor, N. and Sciortino, G. (2013), Stranieri e disuguali-Le disuguaglianze nei diritti e nelle condizioni di vita degli immigrati, Il Mulino, Bologna.

Schwab, K. and Sala-i-Martin, X. (2015), World Economic Forum's Global Competitiveness Report, 2014-2015, World Economic Forum, Switzerland, available at: http://reports.weforum.org/ global-competitiveness-report-2014-2015/ (accessed 3 September 2019).

Shulman, S. (1987), "Discrimination, human capital, and black-white unemployment: evidence from cities", Journal of Human Resources, Vol. 22 No. 3, pp. 361-376.

Torrent-Sellens, J., Velazco-Portocarrero, J. and Viñas-Bardolet, C. (2018), "Knowledge-based work and job satisfaction: evidence from Spain”, Journal of the Knowledge Economy, Vol. 9 No. 2, pp. $575-612$.

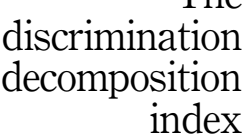

1595 
IJSE

47,12
Venturini, A. and Villosio, C. (2008), "Labour-market assimilation of foreign workers in Italy", Oxford Review of Economic Policy, Vol. 24 No. 3, pp. 517-541.

Zschirnt, E. and Ruedin, D. (2016), "Ethnic discrimination in hiring decisions: a meta-analysis of correspondence tests 1990-2015", Journal of Ethnic and Migration Studies, Vol. 42 No. 7, pp. 1115-1134.

\section{6}

\section{Appendix}

Adding the interacted form in the main equation allows us to compute the marginal effects not only for the single explanatory variables but also for the interaction terms. In general, the marginal effect is an estimation of how much the dependent variable will increase or decrease after a unit change in the independent variable, while the marginal effect of two interacted variables approximates how much one variable $\left(x_{1}\right)$ changes when another variable $\left(x_{2}\right)$ changes. In fact, the marginal effect of a change in both interacted variables is not equal to the marginal effect of a change in the interaction term only (Norton et al., 2004).

In this case, the conditional mean of the dependent variable is:

$$
E\left[y \mid x_{1}, x_{2}, X\right]=\Phi\left(\beta_{1} x_{1}+\beta_{2} x_{2}+\beta_{12} x_{1} x_{2}+X \beta\right)=\Phi(u)
$$

where $\Phi$ is the standard normal cumulative distribution and $u$ indicates the index of independent variables, and in a nonlinear model, the dependent variable is a nonlinear function of these variables, $\mathrm{F}(u)$. If we consider two interacted continuous variables, the interaction effect is the double derivative with respect to $x_{1}$ and $x_{2}$, but in our case, we are interested in the interaction effect of two dummy variables.

In this case, the interaction effect is the discrete double difference (Norton et al., 2004):

$$
\begin{aligned}
\frac{\Delta^{2} F(u)}{\Delta x_{1} \Delta x_{2}} & =\frac{\Delta\left\{F\left(\beta_{1} x_{1}+\beta_{2} x_{2}+\beta_{12} x_{1} x_{2}+X \beta\right)-F\left(\beta_{2} x_{2}+X \beta\right)\right\}}{\Delta x_{2}} \\
& =F\left(\beta_{1}+\beta_{2}+\beta_{12}+X \beta\right)-F\left(\beta_{1}+X \beta\right)-F\left(\beta_{2}+X \beta\right)+F(X \beta)
\end{aligned}
$$

The standard error for the interaction effect of two dummy variables is derived by the Delta method (Ai and Norton, 2003; Greene, 2003) and the asymptotic variance of the estimated interaction effect is estimated consistently by:

$$
\frac{\partial}{\partial \beta^{\prime}}=\left\{\frac{\Delta^{2} F(u)}{\Delta x_{1} \Delta x_{2}}\right\} \widehat{\Omega}_{\beta} \frac{\partial}{\partial \beta}\left\{\frac{\Delta^{2} F(u)}{\Delta x_{1} \Delta x_{2}}\right\}
$$

where $\widehat{\Omega}_{\beta}$ is the consistent covariance estimator of $\widehat{\beta}$.

Therefore, the global effect of the interaction is a function of the coefficients for each interacted variable, the values of all variables and the coefficient for the interaction. This implies that the sign of the interaction coefficient could not indicate the real direction of the interaction effect and that the significance of the interaction effect cannot be determined by the significance of the interaction coefficient. Thus, the statistical significance of the cross-partial derivate cannot be tested by an asymptotic $z$-statistics on $\beta_{12}$ (Eqn 3). As suggested by Ai and Norton (2003), the cross-partial effect in a nonlinear model could be different from zero even if $\beta_{12}=0$ and the test for the statistical significance of the interaction effect must be based on the estimated cross-partial derivative, not on the coefficient of the interaction term.

\section{About the authors}

Giovanni Busetta is an assistant professor in Economic Statistics at the University of Messina. His research interests in applied statistics are focussed on discrimination in the labour market against several minority groups (obese, immigrant and unattractive people), on income inequalities, on Okun's law and on credit market. 
Maria Gabriella Campolo is an associate professor in Social Statistics at the University of Messina. Her research interests in statistical methodology are focussed on the relationship between fertility, women labour supply, time use and well-being. Her studies have been published as book chapters and scientific journal articles. Maria Gabriella Campolo is the corresponding author and can be contacted at: mgcampolo@unime.it

Demetrio Panarello is currently a research fellow in Statistics at the University of Udine. His present research mostly turns towards the statistical analysis of well-being and pro-environmental behaviour. Besides, he has published a number of articles about job market discrimination, estimation theory, financial risk evaluation, judicial statistics and human capital mobility. 